\title{
Genetic Profile of Insertion Mutations in Mouse Leukemias and Lymphomas
}

\author{
Gwenn M. Hansen, Darlene Skapura, and Monica J. Justice ${ }^{1}$ \\ Department of Molecular and Human Genetics, Baylor College of Medicine, One Baylor Plaza, Houston, Texas 77030 USA
}

\begin{abstract}
Murine leukemia retroviruses (MuLVs) cause leukemia and lymphoma in susceptible strains of mice as a result of insertional mutation of cellular proto-oncogenes or tumor suppressor genes. Using a novel approach to amplify and sequence viral insertion sites, we have sequenced $>200$ viral insertion sites from which we identify $>35$ genes altered by viral insertion in four AKXD mouse strains. The class of genes most frequently altered are transcription factors, however, insertions are found near genes involved in signal transduction, cell cycle control, DNA repair, cell division, hematopoietic differentiation, and near many ESTs and novel loci. Many of these mutations identify genes that have not been implicated in cancer. By isolating nearly all the somatic viral insertion mutations contributing to disease in these strains we show that each AKXD strain displays a unique mutation profile, suggesting strain-specific susceptibility to mutations in particular genetic pathways.
\end{abstract}

AKXD recombinant inbred (RI) strains of mice develop a variety of hematopoietic cancers as a consequence of somatic viral insertions that alter the expression of cellular proto-oncogenes and tumor suppressor genes (Mucenski et al. 1986, 1987; Gilbert et al. 1993). Viral insertion site cloning within these strains has led to the identification of many proto-oncogenes as well as tumor suppressor genes, however, the majority of insertion mutations contributing to disease in these strains have not been identified, and few genes altered by viral insertion in B-cell leukemia have been cloned (van Lohuizen and Berns 1990).

Ideally, to determine the molecular genetic basis of leukemia and lymphoma, every somatic mutation contributing to disease should be identified. AKXD animals have proved to be extremely useful as genetic models of disease because affected genes are "tagged" by viral sequences. Unfortunately, current methods for identifying affected genes require the construction and screening of genomic libraries from individual tumor samples. Although effective, this approach is both time and labor intensive and has been the primary hindrance to identifying all virally induced somatic mutations. To avoid unnecessary cloning steps and speed identification of disease-causing mutations we used a novel approach to amplify and sequence viral insertion sites. This approach is based on a technique known as restriction-site PCR, which uses restriction enzyme (RE) recognition sequences as targets in unknown genomic DNA, enabling amplification between unknown genomic DNA and a known sequence. We used this technique to amplify genomic DNA-flanking murine proviral sequences. The viral insertion site amplification technique, or VISA, was used to screen tumors

\footnotetext{
'Corresponding author.
}

E-MAIL mjustice@bcm.tmc.edu; FAX (713) 798-1489. that arose in animals from AKXD RI mouse strains susceptible to B-cell leukemia and lymphoma. This screen identified the majority of virally induced somatic mutations within these tumors. Our approach greatly simplifies the effort needed to access cancer-causing mutations in the AKXD strains, providing an effective means for determining the molecular genetic basis of leukemia and lymphoma.

\section{RESULTS}

AKXD strains susceptible to B-cell leukemia or lymphoma (Mucenski et al. 1987; Gilbert et al 1993) were aged to collect tumors for analysis. Similar to previous studies, the AKXD mice showed strain-specific variation in their susceptibility to disease. The highest incidence of disease was observed in AKXD-18 animals, where $67 \%$ (42 of 63) developed either leukemia or lymphoma by 18 months of age. Animals from both the AKXD-13 and AKXD-27 strains showed moderate susceptibility, with $31 \%$ (18 of 58) and 55\% (41 of 74) affected (respectively). In contrast, only 14\% (4 of 29) of AKXD-10 animals developed disease.

To evaluate the VISA technique, tumors from these strains were screened using VISA to identify somatic viral insertion mutations (Fig. 1). A total of 217 genomic/proviral sequences were identified from screening 107 leukemias and lymphomas. These sequences represent 31 endogenous proviral elements and 186 somatic viral insertion site tags (VSTs). No VST sequences were identified from tumors that did not contain somatically acquired viruses detectable by Southern blot hybridization (data not shown). Database searches of the somatic VSTs identified 31 genes and expressed sequence tags (ESTs) in the nr-DNA and dbEST databases, several of which are known oncogenes or previously identified viral insertion sites (Table 1). Multiple VSTs representing independent in- 
$a$

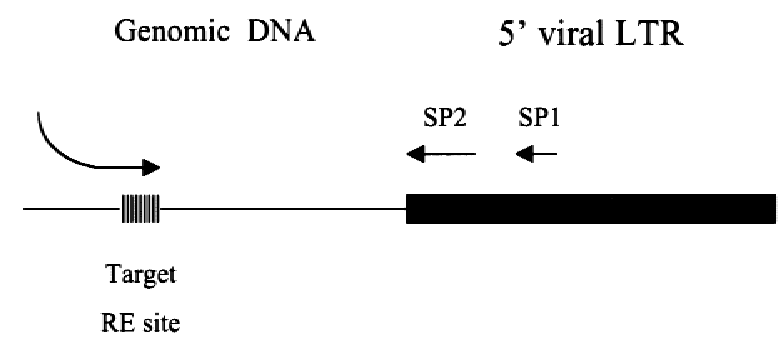

$b$

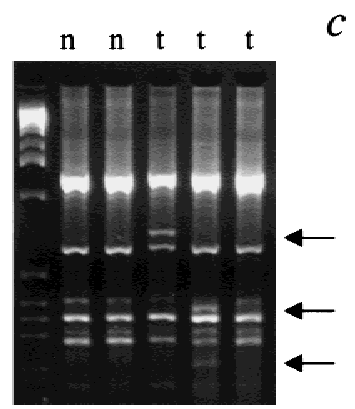

$c$

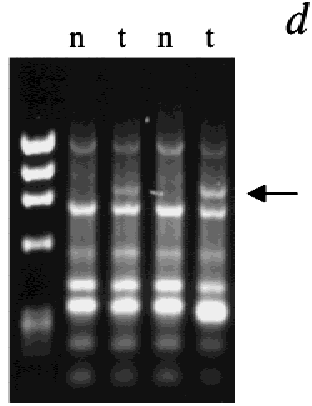

$d$

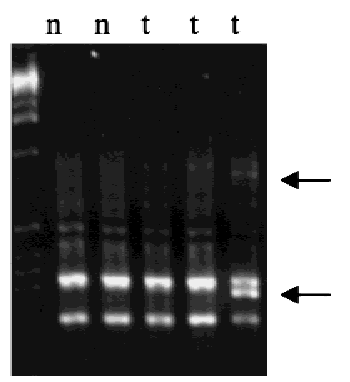

Figure 1 VISA PCR using MuLV LTR-specific primers. (a) Schematic representation of VISA. Viral insertion sites are amplified using primers specific for the long terminal repeat (LTR) of the MuLV in combination with RE-anchored degenerate primers that amplify from flanking genomic DNA. Two rounds of PCR are performed on unmodified genomic DNA using nested virus-specific primers to ensure specificity. Successful amplification of any viral insertion site is dependent on whether the RE anchor sequence is present in the genomic sequence flanking the viral LTR. Therefore, to increase the number of insertion mutations amplified, a minimum of five RE-anchored degenerate primers are used on each sample. The approximate binding sites for LTR specific primers SP1 and SP2 are shown. The RE-anchored degenerate primer contains an M13F linker (shown as a curved line) that is not expected to bind mouse DNA during the first round of PCR, but is useful for subsequent amplifications and sequencing. The stripped box indicates the location of the restriction enzyme recognition site target for the RE-anchored degenerate primer. $(b-d)$ Representative examples of VISA products generated with RE-anchored primers specific for HindIII (b), EcoRI (c), and Bcll (d). DNA isolated from brain tissue, which is rarely infiltrated by tumor cells, was used as a control to identify all nontarget amplification products such as endogenous proviral insertion sites, internal provirus sequences, or single primer amplification products generated by the restriction-site anchored primer. Tumor-specific VISA products, ranging in size from $50 \mathrm{bp}$ to $2.0 \mathrm{~Kb}$ were gel purified and sequenced directly (identified by arrows). Lane designations are (n) (nontumor); ( $\mathrm{t}$ ) tumor.

sertion mutations at Lvis1, Evi3, and Nmyc were identified (Table 1). To determine whether VISA screening identified additional common insertion sites, the remaining set of VST sequences were compared with each other to determine whether multiple independent insertions occurred at the same genetic locus. These comparisons identified three new common sites of viral insertion, designated Lvis2, Lvis3, and Lvis4. Each of these loci were mapped by interspecific backcross to identify candidate genes. Lvis2 cosegregates with marker D7Mit237 on mouse chromosome 7 (Fig. 2a). No viral insertion sites have been mapped to this location; however, three genes are closely linked to this marker: stromal cell interacting factor 1 (Stim1), protein tyrosine phosphatase, nonreceptor type 5 (Ptpn5), and the SRY-box containing gene 6 (Sox6) (Mouse Genome Database 1999). Both Sox6, a transcription factor, and Ptpn5, a protein tyrosine phosphatase, have functions consistent with known oncogenes. Stim 1 is a stromal cell surface molecule identified for its ability to promote the survival or proliferation of pre-B cells in culture (Oritani and Kincade 1996). Although little additional information regarding Stim1 function is available, the expression and proposed function for Stim1 make it an interesting candidate disease gene. Lvis3 cosegregates with markers on chromosome 13 and is tightly linked to the Fim1 locus (Fig. 2b). Fim 1 is a common site of viral insertion in myeloblastic leukemias for which the affected gene has not yet been identified (Sola et al. 1986). Comparisons of restriction map data from Fim1 and Lvis3 indicate that these loci do not overlap (data not shown); however, further studies will be necessary to determine whether viral insertions at Lvis 3 and Fim1 affect the same gene. Lvis4 maps to distal chromosome 12, near the homeobox transcription factor goosecoid, and the T-cell leukemia translocation breakpoint TCL1 (Virgilio et al. 1994; Mouse Genome Database 1999).

VISA screening identified 186 insertion mutations from 107 tumors. To estimate the percentage of total insertion mutations identified in the current study, Southern blot hybridizations were performed using probes for selected loci. Screening at Evi3, Lvis1, Hex, Alx4, and Rel detected proviral insertions in addition to those identified by VISA, whereas no additional alterations were identified using probes for RecQ5 or Erp72 (Table 1). These screens identified a total of 26 insertions, 17 of which were amplified and sequenced using VISA (65\%). This is consistent with previous studies, which have indicated that most AKXD leukemias and lymphomas contain three to four somatic viral insertions (Mucenski et al. 1988; Gilbert et al. 1993), and suggests that although the majority of mutations have been identified, additional screening with degenerate primers targeting other restriction enzyme sequences will be necessary to identify all mutations.

The frequency of insertions at many of these loci varied significantly between AKXD strains. Although 
Table 1. Sequence Identity of Loci Disrupted by Viral Insertion

\begin{tabular}{|c|c|c|c|c|c|c|}
\hline Tumor & Common site & Candidate gene $(s)^{a}$ & Position $^{\mathbf{b}}$ & Protein product & Type $^{c}$ & VST ID ${ }^{d}$ \\
\hline $18-18$ & Lvis1 & Hex, Eg5 & IG & homeobox transcription factor (Hex), & B & 18018G1 \\
\hline $18-28$ & Lvis1 & & IG & kinesin-related spindle protein (Eg5) & $\mathrm{T}$ & 18028G1 \\
\hline $18-95$ & Lvis 1 & & IG & & B & $18095 \mathrm{G} 2$ \\
\hline 18-132 & Lvis1 & & IG & & B & $18132 \mathrm{G} 1$ \\
\hline $13-16$ & Lvis1 & & IG & & B & 13016G1 \\
\hline 13-107 & Lvis1 & & IG & & B & 13107G1 \\
\hline $18-153$ & Lvis1 & & IG & & $\mathrm{B} / \mathrm{T}$ & 18153G1 \\
\hline $18-91$ & Lvis1 & & IG & & B & S \\
\hline $27-28$ & Lvis 1 & & IG & & B & $\mathrm{s}$ \\
\hline 27-193 & Lvis1 & & IG & & B & $\mathrm{S}$ \\
\hline $27-16$ & Evi3 & Evi3 & UN & unknown & B & $27016 \mathrm{G} 2$ \\
\hline $27-57$ & Evi3 & & UN & & B & $27057 \mathrm{G} 8$ \\
\hline $27-183$ & Evi3 & & UN & & B & $27183 G 3$ \\
\hline $27-205$ & Evi3 & & UN & & B & $27205 \mathrm{G} 8$ \\
\hline $27-207$ & Evi3 & & UN & & $S$ & 27207G1 \\
\hline $27-258$ & Evi3 & & UN & & B & $27258 \mathrm{G} 3$ \\
\hline $27-222$ & Evi3 & & UN & & B & S \\
\hline $27-172$ & Evi3 & & UN & & B & $\mathrm{S}$ \\
\hline $18-49$ & $N-m y c$ & $N-m y c$ & $5^{\prime} \mathrm{E}$ & nuclear protein & $\mathrm{B} / \mathrm{T}$ & 18049G1 \\
\hline $18-109$ & $N-m y c$ & & $5^{\prime} \mathrm{E}$ & & $\mathrm{B} / \mathrm{T}$ & 18109G1 \\
\hline $27-215$ & $N-m y c$ & & 3' UTR & & $\mathrm{T}$ & $27215 \mathrm{G} 1$ \\
\hline $18-60$ & Lvis2 & unknown & UN & unknown & S & $18060 \mathrm{G} 6$ \\
\hline $18-67$ & Lvis2 & & UN & & S & $18067 \mathrm{G} 2$ \\
\hline $27-110$ & Lvis2 & & UN & & $\mathrm{T}$ & $27110 \mathrm{G} 1$ \\
\hline $18-72$ & Lvis3 & unknown & UN & unknown & B & $18072 \mathrm{G} 2$ \\
\hline $18-132$ & Lvis3 & & UN & & B & $18132 \mathrm{G} 2$ \\
\hline $10-60$ & Lvis4 & unknown & UN & unknown & $\mathrm{B} / \mathrm{T}$ & $10060 \mathrm{G} 2$ \\
\hline $27-266$ & Lvis4 & & UN & & B & $27266 \mathrm{G} 1$ \\
\hline $18-34$ & Lvis5 & Alx4 & $\mathrm{P}$ & paired-type homeobox transcription factor & $\mathrm{T}$ & $18034 \mathrm{G} 2$ \\
\hline $27-110$ & Lvis5 & & UN & & $\mathrm{T}$ & S \\
\hline 27-189 & Lvis7 & Rel & $5^{\prime}$ & transcription factor & B & $27189 \mathrm{G} 3$ \\
\hline $27-17$ & Lvis7 & & UN & & $S$ & S \\
\hline $27-129$ & Lvis6 & Hex & $3^{\prime}$ UTR & homeobox transcription factor & $S$ & S \\
\hline $27-268$ & Lvis6 & & 3' UTR & & $B / T$ & $\mathrm{~S}$ \\
\hline $27-28$ & Lvis ${ }^{\mathrm{e}}$ & $\mathrm{CcnD} 3$ & C & D cyclin & B & $27028 \mathrm{C} 5$ \\
\hline $27-178$ & Lvis9e & Sox 4 & $3^{\prime}$ UTR & HMG-box transcription factor & B & $27178 \mathrm{G} 1$ \\
\hline 27-94 & Gfi1 & Gfi1 & 3' UTR & zinc finger transcription factor & $\mathrm{T}$ & $27094 G 3$ \\
\hline $18-123$ & Myc & Myc & $\mathrm{P}$ & nuclear protein & $\mathrm{B} / \mathrm{T}$ & $18123 \mathrm{G} 2$ \\
\hline $13-23$ & Notch1 & Notch1 & 3' UTR & cell surface receptor & $\mathrm{T}$ & 13023G1 \\
\hline $27-16$ & & $N$-ras & $5^{\prime}$ & GTP-binding protein & B & $27016 \mathrm{G} 1$ \\
\hline 27-107 & & Cd5 & $5^{\prime}$ & cell surface receptor & $\mathrm{S}$ & $27107 \mathrm{C} 1$ \\
\hline $27-3$ & & Erp72 & $\mathrm{P}$ & endoplasmic reticulum protein & B & $27003 C 4$ \\
\hline $18-33$ & & $\mathrm{lgH}$ & $3^{\prime} \mathrm{E}$ & B-cell surface receptor & $B / T$ & $18033 \mathrm{G} 3$ \\
\hline 10-11 & & Mzfp2-related & C & zinc finger transcription factor & B & $10011 \mathrm{C} 3$ \\
\hline $27-28$ & & RecQ5 & $\mathrm{C}$ & DNA helicase & B & $27028 C 2$ \\
\hline $18-97$ & & $\operatorname{sip} 1$ & $3^{\prime}$ UTR & spliceosomal snRNP biogenesis & S & 18097G2 \\
\hline $27-30$ & & $18 \mathrm{~S}$ rRNA & intron & rRNA & B & $27030 G 1$ \\
\hline $18-43$ & & U96726 & IG & putative phosphoinositide 5-phosphatase type II & B & 18043G4 \\
\hline $27-28$ & & Al250289 & & NCI CGAP Lym 12 follicular lymphoma EST & B & $27028 \mathrm{E} 1$ \\
\hline $27-3$ & & N22410 & & EST & B & $27003 \mathrm{E} 5$ \\
\hline $18-123$ & & Al549667 & & EST & $\mathrm{B} / \mathrm{T}$ & $18123 \mathrm{E} 1$ \\
\hline $27-258$ & & AA611619 & & EST & B & $27258 \mathrm{E} 2$ \\
\hline $27-3$ & & AA546050 & & EST & B & $27003 \mathrm{E} 2$ \\
\hline $27-24$ & & Al059755 & & EST & $\mathrm{T}$ & $27024 \mathrm{E} 2$ \\
\hline $13-36$ & & AA636183 & & EST & B & 13036E1 \\
\hline $13-87$ & & AA207479 & & EST & $\mathrm{T}$ & 13087E1 \\
\hline $13-44$ & & Al644018 & & EST & N.D. & $13044 \mathrm{E} 1$ \\
\hline $13-53$ & & Al615534 & & EST & B & 13053E1 \\
\hline $13-45$ & & AA990077 & & EST & S & $13045 \mathrm{E} 1$ \\
\hline $13-37$ & & AA1614004 & & EST & B & 13037E1 \\
\hline
\end{tabular}

Viral insertion sites identified using VISA or conventional Southern analysis are listed, except sites for which genes have not been identified (135 VSTs), or those representing endogenous insertion sites. All VISA products represent sequence $5^{\prime}$ of the proviral element (except Evi3 tags, which are $3^{\prime}$ insertion sites), such that each insertion is identified only once.

${ }^{a}$ GenBank accession nos. are given for ESTs and genomic sequence contigs.

bLocation of inserted viral element in relation to candidate gene as determined by Blast sequence alignment. [(C) coding; (E) enhancer; (IG) intergenic; (P) promoter; (UN) unknown; (UTR) untranslated region].

'Tumor cell type was determined by Southern analysis [(B) B cell; (T) T cell; (B/T) mixture of B and T cell; (S) progenitor or myeloid; (N.D.) not determined].

dSequences have been deposited in GenBank, but can also be accessed at http://www.mouse-genome.bcm.tmc.edu/. [(S) insertion sites identified by conventional Southern analysis].

eViral insertions at this locus were identified in other tumor subsets, indicating that this is a common site. 
$a$

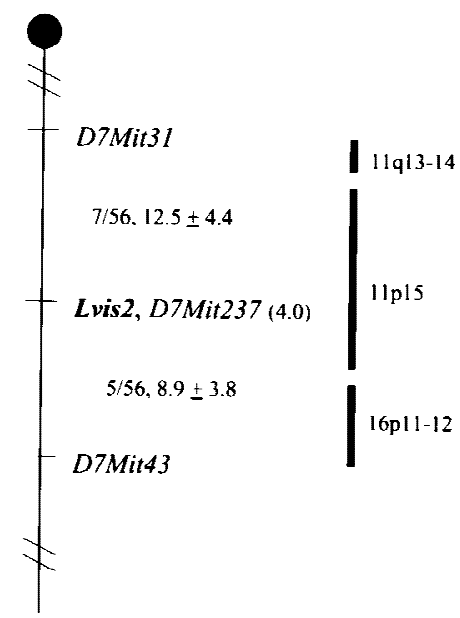

$b$

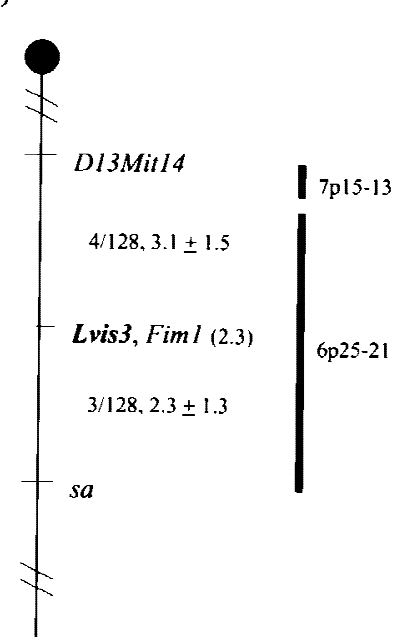

$c$

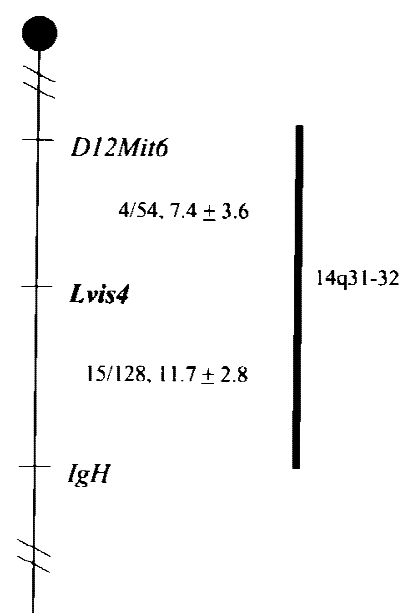

Figure 2 Meiotic mapping of Lvis2-Lvis4. Lvis viral insertion sites were mapped using an (SB/Le $\times$ M. spretus) $\mathrm{F}_{1} \times \mathrm{SB} /$ Le interspecific backcross previously typed for multiple markers on all mouse chromosomes (Justice et al. 1990). Partial linkage maps of chromosomes $7(a), 13(b)$, and $12(c)$ are depicted. Ratios of the total number of mice exhibiting recombinant chromosomes to the total number of mice analyzed for each pair of loci (with map distances in centimorgans \pm the standard error) are shown to the left of each chromosome. For markers that cosegregate, the upper $95 \%$ confidence interval is shown in parentheses. The predicted map locations of human orthologs are indicated to the right of each chromosome. References and additional information regarding human map locations can be obtained from the Mouse Genome Database (http://www.informatics.jax.org/).

insertions at several loci such as Evi3, Lvis3, and c-Rel are strainspecific, insertions at Alx4, Lvis1, Lvis2, and Lvis4 were observed in multiple strains (Table 2). In addition, several insertion mutations show tumor celltype specificity, occurring primarily in B-lineage tumors (Evi3, Lvis1, Lvis3) or T-lineage tumors (Alx4). No- tably, insertions at Evi3 and Lvis1 occur frequently in these strains, and likely play a significant role in B-cell disease.

\section{DISCUSSION}

The majority of virally induced somatic mutations in

Table 2. Strain-Specific Mutation Profile

\begin{tabular}{|c|c|c|c|c|c|c|}
\hline \multirow{2}{*}{$\begin{array}{l}\text { Common } \\
\text { site }\end{array}$} & \multirow[b]{2}{*}{ Gene } & \multirow{2}{*}{$\underset{\text { location }^{a}}{\text { Map }}$} & \multicolumn{4}{|c|}{ Insertion frequency $(\%)^{b}$} \\
\hline & & & AKXD-10 & AKXD13 & AKXD-18 & AKXD-27 \\
\hline Lvis1 & Hex, Eg5 & $19(26)^{c}$ & 0 & 11 & 14 & 5 \\
\hline Lvis2 & unknown & $7^{c}$ & 0 & 0 & 5 & 2 \\
\hline Lvis3 & unknown & $13^{c}$ & 0 & 0 & 5 & 0 \\
\hline Lvis4 & unknown & $12^{c}$ & $1 / 4$ & 0 & 0 & 2 \\
\hline Lvis5 & Alx4 & $2(65)$ & 0 & 0 & 2 & 2 \\
\hline Lvis6 & Hex & $19(26)^{c}$ & 0 & 0 & 0 & 5 \\
\hline Lvis7 & Rel & $11(13)$ & 0 & 0 & 0 & 5 \\
\hline Lvis8 & CcnD3 & 17 & 0 & 0 & 0 & 2 \\
\hline Lvis9 & Sox4 & 13 & 0 & 0 & 0 & 2 \\
\hline Evi3 & Evi3 & $18(5)^{\mathrm{c}}$ & 0 & 0 & 0 & 20 \\
\hline$N-m y c$ & $N-m y c$ & $12(4)$ & 0 & 0 & 5 & 2 \\
\hline Gfir & Gfi1 & $5(56)$ & 0 & 0 & 0 & 2 \\
\hline Myc & Myc & $15(32)$ & 0 & 0 & 2 & 0 \\
\hline Notch1 & Notch1 & $2(15)$ & 0 & 6 & 0 & 0 \\
\hline
\end{tabular}

${ }^{a}$ Mouse chromosomal map locations either were determined in our laboratory or are based on published data. Primary mapping data are available from the Mouse Genome Informatics database (http:// informatics.jax.org). Numbers in parentheses represent estimated distance from the centromere in centimorgans as assigned by MGD.

${ }^{b}$ Insertion frequency is calculated from a total of 18 AKXD-13 tumors, 42 AKXD-18 tumors and 41 AKXD27 tumors, where the AKXD-10 frequency is shown as a fraction due to the number of tumors analyzed (4). ${ }^{c}$ Map locations determined using an (SB/Le $\times M$. spretus) $\mathrm{F}_{1} \times \mathrm{SB} /$ Le interspecific backcross (Justice et al. 1990). 
primary leukemias and lymphomas from four AKXD strains were identified by direct amplification and sequencing using VISA. Viral insertions were identified at the common insertion sites Evi3, Lvis1, Gfi1, Myc, Notch1, and Nmyc, at eight new common insertion sites, Lvis2-Lvis9, and at many other genes and ESTs not previously implicated in cancer.

Multiple insertions were identified at Lvis1, the most frequently altered locus in AKXD B-cell neoplasias (Hansen and Justice 1999). Viral insertions at this site activate the expression of two distant genes, Eg5 and Hex (Hansen and Justice 1999). EG5 is a kinesinrelated spindle protein necessary for spindle assembly and cell division. The role of kinesin-related proteins in cancer is unclear; however, direct inhibition of Eg5 has been shown to block mitosis by inhibiting bipolar spindle formation (Mayer et al. 1999). Hex is a divergent homeobox gene implicated in hematopoietic differentiation and transcriptional repression (Manfioletti et al. 1995; Tanaka et al. 1999). Homeobox genes and related transcription factors play a significant role in leukemia and lymphoma (Look 1997). In addition to insertions at Lvis1, insertions at Lvis6 identify a common viral insertion site near the 3' UTR of Hex in AKXD-27 tumors, providing additional evidence for the role of Hex in B-cell disease.

Multiple viral insertions were identified at Lvis5, a common site of viral insertion in the promoter region of the homeobox transcription factor Alx4. This gene contains a single paired-type DNA binding domain similar to the Drosophila "aristaless" protein (Qu et al. 1997). In the mouse, Alx4 is expressed during early embryogenesis but is not expressed in later stages of development or in adult tissues (Qu et al. 1997). Mutations in Alx4 produce preaxial polydactyly as well as a variety of other skeletal defects (Qu et al. 1998). The somatic mutations identified in this study provide the first evidence linking Alx4 to cancer.

The common insertion site Lvis7 identifies the Rel oncogene, belonging to the REL/NF-кB/IкB superfamily of signal transducers and transcription factors that carry out diverse functions in the immune system. Rel was initially identified as the mammalian homolog of the viral oncogene v-REL, which has been shown to promote cellular transformation both in vitro and in vivo (Sylla and Temin 1986; Moore and Bose 1988; Foo and Nolan 1999). Current studies suggest that the mechanism through which Rel and other family members mediate cellular transformation involves inappropriate protection or rescue from apoptotic signals (Foo and Nolan 1999). Notably, although Rel has been implicated in lymphoma development, our study is the first to identify it as a common viral insertion site, demonstrating the efficacy of the VST technique for identifying cancer-causing genes.

Many of the known AKXD disease genes were identified using VISA. However, insertions near Pim1, Evi1, Fis1, and Pvt1, which have been observed in AKXD tumors (Mucenski et al. 1987, 1988), were not identified in this study. Insertion mutations at these sites occur infrequently in the four AKXD strains screened by VISA; therefore, it is possible that insertions at these sites do not occur in this tumor subset. Alternatively, although we have isolated the majority of insertion mutations, additional screening may be necessary to identify all genes altered. It is also important to note that previous studies used Southern blot hybridization to screen several kilobases of genomic DNA at each locus, little of which is represented in current sequence databases. This is certainly the case for Fis1, where no sequence data is available.

A large number of the viral insertion site sequences did not show similarity to each other or to sequences in available databases (135 of 186 , or $73 \%$ ). These insertions may lie at a distance from candidate genes, or may occur within introns or near $5^{\prime}$ or $3^{\prime}$ regulatory elements for which sequence is not available. Alternatively, they may identify novel genes. Several VSTs showed similarity to mouse, human, and rat ESTs, one of which is a CGAP EST expressed in human follicular lymphoma (Table 1). Cross-referencing mutation and sequence databases such as these is likely to reveal roles for many novel genes. Identification of candidate genes for the remaining VSTs is essential for a complete understanding of hematopoietic diseases, and will require forthcoming genomic sequence information from mouse and human genome sequencing efforts (Collin et al. 1998; Battey et al. 1999).

For sites where genes can be immediately identified, it is clear that many have the potential to contribute to the disease process. Insertions near CcnD3, Gfi1, Myc, Notch1, Nras, and Sox4 were each observed once. These genes have been identified as cellular proto-oncogenes or common viral insertion sites in other tumor subsets or model systems (Corcoran et al. 1984; Gilks et al. 1993; Steffen 1984). Obviously none of these loci play a significant role overall in the disease process observed in these AKXD strains. Nonetheless, a viral insertion mutation near any one of these genes would likely provide a growth advantage to the individual tumor in which it occurred. Certainly any of the genes identified near viral insertion sites could contribute to disease. One gene of particular interest is RecQ5. RecQ helicases function in DNA repair, recombination, and replication. Mutations in three of the five human RecQ proteins are associated with diseases involving predisposition to malignancies and increased chromosomal instability (Ellis et al. 1995; Yu et al. 1996; Kitao et al. 1999). Recent mapping of RecQ5 has localized this gene to human chromosome 17q23-25, a region associated with both breast and ovarian cancer (Sekelsky et al. 1999). Our data identify RecQ5 as a potential proto- 
oncogene in mouse leukemia, and suggest that further study of RecQ5 in cancer is warranted.

In addition to implicating multiple loci in hematopoietic disease, analysis of VSTs revealed distinct mutation profiles within AKXD strains. This implies that although a variety of genes can contribute to malignant transformation, susceptibility alleles within each genetic background determine mutation oncogenicity. Although further work will be necessary to identify these susceptibility alleles, the VSTs represent the majority of genes that contribute to disease onset and progression within the hematopoietic lineages of these strains. These data can be integrated with both genomic and gene expression profiles from human cancers to uncover the pathways involved in the development of leukemia and lymphoma in both mouse and human.

\section{METHODS}

\section{Mice}

Mice from four AKXD strains, AKXD-10, AKXD-13, AKXD-18, and AKXD-27, were obtained from The Jackson Laboratory and maintained in our colony at Oak Ridge National Laboratory. Animals were monitored weekly for signs of illness, and moribund animals or healthy animals reaching the age of 18 months were autopsied and evaluated for signs of lymphoma. Normal and affected tissues were snap-frozen in liquid nitrogen.

\section{DNA Extraction}

High molecular weight DNA was isolated from tumorinfiltrated and normal tissues as described (Wu et al. 1995), followed by a single phenol/chloroform extraction and ethanol precipitation following standard procedures (Sambrook et al. 1989).

\section{Overview of VISA}

Mouse genomic sequence flanking inserted proviral elements was amplified using two rounds of PCR. The initial PCR was performed on $200 \mathrm{ng}$ of genomic DNA using a restriction site-anchored degenerate primer (Sarkar et al. 1993) and a MuLV long terminal repeat (LTR)-specific primer (SP1). The second round PCR was performed using $1 \mu \mathrm{l}$ of first round reaction as template, with a nested LTR-specific primer (SP2) and the M13F primer, which is included as an adapter in the degenerate primer design. Second-round PCR products were separated by gel electrophoresis, and tumor-specific VISA products were purified and sequenced (Fig. 1).

\section{Oligonucleotide Primers}

Nested primers specific to the ecotropic MuLV LTR were designed to amplify the upstream insertion junction. These primers (first round) SP1 5'-CTGAGAACATCAGCTCTG-3' and (second round) SP2 5'-CTGGCTAAGCCTTATGAAGGGGTCTTTC-3' bind 70 bp and 1 bp from the 5' LTR terminus, respectively. To amplify sequences downstream of the proviral element, primers (first round) 5'-AATCAGCTCGCTTCTCGC-3' and (second round) 5'-GAGGGTCTCCTCAGAGTGATTGACTGC-3' were used, binding $223 \mathrm{bp}$ and $21 \mathrm{bp}$ from the 3' LTR terminus, respectively. The degenerate primer design consisted of three regions: an anchor sequence of four to six nucleotides based on RE recognition sequences, a fully degenerate region of eight nucleotides, and an adapter region consisting of the M13F primer sequence (for example, to target the restriction enzyme recognition sequence EcoRI, 5'GGGTTTTCCCAGTCACGACNNNNNNNNGAATTC-3'). Primers targeting EagI, EcoRI, HindIII, SacI, and $\mathrm{XbaI}$ were used on all tumor samples. Additional screens using primers for BclI, BssHII, PstI, SacII, or TaqI were performed on those samples not generating products after the initial screen.

\section{PCR Conditions}

PCR was performed using a MJ Research thermal controller with the cycling parameters: $94^{\circ} \mathrm{C}$ for $3 \mathrm{~min}, 30$ cycles of $94^{\circ} \mathrm{C}$ for $30 \mathrm{sec}, 50^{\circ} \mathrm{C}$ for $2 \mathrm{~min}$, and $72^{\circ} \mathrm{C}$ for $2 \mathrm{~min}$, with a final 7 -min incubation at $72^{\circ} \mathrm{C}$. The initial round of PCR contained $200 \mathrm{ng}$ of genomic DNA, 2.5 pmoles of SP1, 25 pmoles of degenerate primer, $1.5 \mathrm{~mm} \mathrm{MgCl}, 0.2 \mathrm{~mm}$ each dNTP, $2.5 \mu \mathrm{l}$ $10 \times$ PCR buffer, $1 \mathrm{~m}$ betaine, and $0.25 \mu \mathrm{l} \mathrm{Taq}$ DNA polymerase in a volume of $25 \mu \mathrm{l}$. One microliter of this reaction was used as template in a nested reaction with the following changes: 25 pmoles of both SP2 and M13F were used as primers, and the annealing temperature was increased to $55^{\circ} \mathrm{C}$. Each reaction was electrophoresed on a $2 \%$ SeaPlaque GTG agarose gel in $1 \times$ TAE. Products of interest were purified using the QIAquick gel extraction kit (Qiagen) and sequenced using the M13F and SP2 primers.

\section{DNA Sequencing and Analysis}

DNA was sequenced using the ABI Prism BigDye Terminator Cycle Sequencing Kit (Perkin Elmer) on an ABI model 377 DNA Sequencer (Applied Biosystems). Sequence files were edited to remove ambiguous bases and were analyzed for sequence overlap using Sequencher (Gene Codes Corporation Inc.). Sequence from each product was verified to contain the target RE sequence and viral LTR sequence. Sequences representing endogenous proviral elements were identified by comparison with sequenced products amplified from nontumor DNA. In cases were a single insertion mutation was amplified more than once by different RE-anchored degenerate primers, only the largest sequence was used. Edited sequence files were searched against available sequence databases using the gapped BLAST algorithms BLAST-nr, BLASTN-dbEST, and BLASTX-nr (Gish and States 1993; Altschul et al. 1997).

\section{Genetic Mapping}

Loci were mapped using an (SB/Le $\times$ M. spretus) $\mathrm{F}_{1} \times \mathrm{SB} / \mathrm{Le}$ interspecific backcross previously typed for multiple markers on all mouse chromosomes (Justice et al. 1990). Informative restriction fragment length polymorphisms were monitored in $130 \mathrm{~N}_{2}$ progeny to determine linkage. Additional information regarding allele sizes and informative polymorphisms has been deposited in the Mouse Genome Database (http:// www.informatics.jax.org).

\section{Southern Blot Analysis}

Membranes were prehybridized and hybridized as described (Church and Gilbert 1984). Probes for IgH, Igк, J $\beta 1$, and J $\beta 2$ have been described (Kronenberg et al. 1985; Mucenski et al. 1986). Probes representing Lvis1, the 3' UTR of the Hex gene, and the Evi3 insertion site have been described (Justice 1994; Hansen and Justice 1999). All other probes were derived from VISA PCR products. Probes were radioactively labeled using the Prime-It kit (Stratagene). 


\section{Classification of Tumors}

Tumors were classified as B, T, or mixed lineage based on BCR

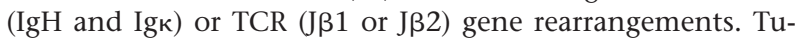
mors showing no BCR or TCR gene rearrangements may represent either progenitor or myeloid tumors (Mucenski et al. 1988).

\section{ACKNOWLEDGMENTS}

We thank Toni Jago for assistance in tissue collection. This work is supported by a grant from the National Cancer Institute (R29CA63229), and by an American Cancer Society Junior Faculty Research Award (JFRA0553) to M.J.J.

The publication costs of this article were defrayed in part by payment of page charges. This article must therefore be hereby marked "advertisement" in accordance with 18 USC section 1734 solely to indicate this fact.

\section{REFERENCES}

Altschul, S., T. Madden, A. Schaffer, J. Zhang, Z. Zhang, W. Miller, and D. Lipman. 1997. Gapped BLAST and PSI-BLAST: A new generation of protein database search programs. Nucleic Acids Res. 25: 3389-3402.

Battey, J., E. Jordan, D. Cox, and W. Dove. 1999. An action plan for mouse genomics. Nature Genet. 21: 73-75.

Church, G. and W. Gilbert. 1984. Genomic sequencing. Proc. Natl. Acad. Sci. 81: 1991-1995.

Collins, F., A. Patrinos, E. Jordan, A. Chakravarti, R. Gesteland, and L. Walters. 1998. New goals for the U.S. Human Genome Project: 1998-2003. Science 282: 682-689.

Corcoran, L., J. Adams, A. Dunn, and S. Cory. 1984. Murine T lymphomas in which the cellular myc oncogene has been activated by retroviral insertion. Cell 37: 113-122.

Ellis, N., J. Groden, T. Ye, J. Straughen, D. Lennon, S. Ciocci, M. Proytcheva, and J. German. 1995. The Bloom's syndrome gene product is homologous to RecQ helicases. Cell 83: 655-666.

Foo, S. and G. Nolan. 1999. NF-kappaB to the rescue: RELs, apoptosis and cellular transformation. Trends Genet. 15: 229-235.

Gilbert, D., P. Neumann, B. Taylor, N. Jenkins, and N. Copeland. 1993. Susceptibility of AKXD recombinant inbred mouse strains to lymphomas. J. Virol. 67: 2083-2090.

Gilks, C., S. Bear, H. Grimes, and P. Tsichlis. 1993. Progression of interleukin-2 (IL-2)-dependent rat T cell lymphoma lines to IL-2-independent growth following activation of a gene (Gfi-1) encoding a novel zinc finger protein. Mol. Cell. Biol. 13: $1759-1768$.

Gish, W. and D. States. 1993. Identification of protein coding regions by database similarity search. Nature Genet. 3: 266-272.

Hansen, G.M. and M.J. Justice. 1999. Activation of Hex and mEg5 by retroviral insertion may contribute to mouse B-cell leukemia. Oncogene 18: 6531-6539.

Justice, M., C. Silan, J. Ceci, A. Buchberg, N. Copeland, and N. Jenkins. 1990. A molecular genetic linkage map of mouse chromosome 13 anchored by the beige (bg) and satin (sa) loci. Genomics 6: 341-351.

Justice, M., H.R. Morse, N. Jenkins, and N. Copeland. 1994. Identification of Evi-3, a novel common site of retroviral integration in mouse AKXD B-cell lymphomas. J. Virol. 68: $1293-1300$

Kitao, S., A. Shimamoto, M. Goto, R. Miller, W. Smithson, N. Lindor, and Y. Furuichi. 1999. Mutations in RECQL4 cause a subset of cases of Rothmund-Thomson syndrome. Nature Genet. 22: 82-84.

Kronenberg, M., J. Goverman, R. Haars, M. Malissen, E. Kraig, L. Phillips, T. Delovitch, N. Suciu-Foca, and L. Hood. 1985. Rearrangement and transcription of the beta-chain genes of the T-cell antigen receptor in different types of murine lymphocytes. Nature 313: 647-653.

Look, A. 1997. Oncogenic transcription factors in the human acute leukemias. Science 278: 1059-1064.
Manfioletti, G., V. Gattei, E. Buratti, A. Rustighi, A. De Iuliis, D. Aldinucci, G. Goodwin, and A. Pinto. 1995. Differential expression of a novel proline-rich homeobox gene (Prh) in human hematolymphopoietic cells. Blood 85: 1237-1245.

Mayer, T., T. Kapoor, S. Haggarty, R. King, S. Schreiber, and T. Mitchison. 1999. Small molecule inhibitor of mitotic spindle bipolarity identified in a phenotype-based screen. Science 286: 971-974.

Mouse Genome Database (MGD). Mouse Genome Informatics. The Jackson Laboratory, Bar Harbor, Maine 1999. World Wide Web (URL: http://www.informatics.jax.org/).

Moore, B. and H.J. Bose. 1988. Transformation of avian lymphoid cells by reticuloendotheliosis virus. Mutat. Res. 195: 75-90.

Mucenski, M., B. Taylor, N. Jenkins, and N. Copeland. 1986. AKXD recombinant inbred strains: models for studying the molecular genetic basis of murine lymphomas. Mol. Cell. Biol. 6: 4236-4243.

Mucenski, M., D. Gilbert, B. Taylor, N. Jenkins, and N. Copeland. 1987. Common sites of viral integration in lymphomas arising in AKXD recombinant inbred mouse strains. Oncogene Res. 2: 33-48.

Mucenski, M., B. Taylor, J. Ihle, J. Hartley, H.C. Morse III, N. Jenkins, and N. Copeland. 1988. Identification of a common ecotropic viral integration site, Evi-1, in the DNA of AKXD murine myeloid tumors. Mol. Cell. Biol. 8: 301-308.

Oritani, K. and P.W. Kincade. 1996. Identification of stromal cell products that interact with pre-B cells. J. Cell. Biol. 134: 771-782.

Qu, S., L. Li, and R. Wisdom. 1997. Alx-4: cNDA cloning and characterization of a novel paired-type homeodomain protein. Gene 203: 217-223.

Qu, S., S. Tucker, J. Ehrlich, J. Levorse, L. Flaherty, R. Wisdom, and T. Vogt. 1998. Mutations in mouse Aristaless-like4 cause Strong's luxoid polydactyly. Development 125: 2711-2721.

Sambrook, J., E. Fritsch, and T. Maniatis. 1989. Molecular cloning: A laboratory manual, 2nd ed. Cold Spring Harbor Laboratory Press, Cold Spring Harbor, NY.

Sarkar, G., R. Turner, and M. Bolander. 1993. Restriction-site PCR: A direct method of unknown sequence retrieval adjacent to a known locus by using universal primers. PCR Methods Appl. 2: 318-322.

Sekelsky, J., M. Brodsky, G. Rubin, and R. Hawley. 1999. Drosophila and human RecQ5 exist in different isoforms generated by alternative splicing. Nucleic Acids Res. 27: 3762-3769.

Sola, B., S. Fichelson, D. Bordereaux, P. Tambourin, and S. Gisselbrecht. 1986. fim-1 and fim-2: Two new integration regions of Friend murine leukemia virus in myeloblastic leukemias. J. Virol. 60: 718-725.

Steffen, D. 1984. Proviruses are adjacent to c-myc in some murine leukemia virus-induced lymphomas. Proc. Natl. Acad. Sci. 81: 2097-2101.

Sylla, B. and H. Temin. 1986. Activation of oncogenicity of the c-rel proto-oncogene. Mol. Cell. Biol. 6: 4709-4716.

Tanaka, T., T. Inazu, K. Yamada, Z. Myint, V. Keng, Y. Inoue, N. Taniguchi, and T. Noguchi. 1999. cDNA cloning and expression of rat homeobox gene, Hex, and functional characterization of the protein. Biochem. J. 339: 111-117.

van Lohuizen, M. and A. Berns. 1990. Tumorigenesis by slow-transforming retroviruses-An update. Biochim. Biophys. Acta. 1032: 213-235.

Virgilio, L., M. Narducci, M. Isobe, L. Billips, M. Cooper, C. Croce, and G. Russo. 1994. Identification of the TCL1 gene involved in T-cell malignancies. Proc. Natl. Acad. Sci. 91: 12530-12534.

Wu, Q., M. Chen, M. Buchwald, and R. Phillips. 1995. A simple, rapid method for isolation of high quality genomic DNA from animal tissues. Nucleic Acids Res. 23: 5087-5088.

Yu, C.-E., J. Oshima, Y. Fu, E. Wijsman, F. Hisama, R. Alisch, S. Matthews, J. Nakura, T. Miki, S. Ouais, G. Martin, J. Mulligan, and G. Schellenberg. 1996. Positional cloning of the Werner's syndrome gene. Science 272: 258-262.

Received October 6, 1999; accepted in revised form December 9, 1999. 


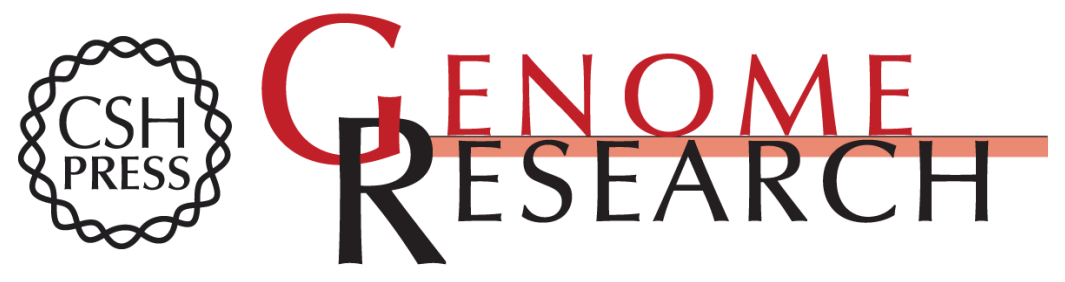

\section{Genetic Profile of Insertion Mutations in Mouse Leukemias and Lymphomas}

Gwenn M. Hansen, Darlene Skapura and Monica J. Justice

Genome Res. 2000 10: 237-243

Access the most recent version at doi:10.1101/gr.10.2.237

References This article cites 34 articles, 17 of which can be accessed free at:

http://genome.cshlp.org/content/10/2/237.full.html\#ref-list-1

\section{License}

Email Alerting Receive free email alerts when new articles cite this article - sign up in the box at the Service top right corner of the article or click here.

\section{Affordable, Accurate Sequencing.}

